\title{
Educação Ambiental no currículo técnico profissionalizante: Uma ferramenta para valorizar o meio ambiente e promover a consciência do aluno sobre a situação do
}

\section{planeta}

Environmental Education in the professionalizing technical curriculum: A tool to value the environment and promote student awareness of the planet's situation

La educación Ambiental en el currículo técnico profesionalizador: Una herramienta para valorar el medio ambiente y promover la conciencia de los estudiantes sobre la situación del planeta

Recebido: 23/01/2021 | Revisado: 24/01/2021 | Aceito: 29/01/2021 | Publicado: 06/02/2021

Javier Dias Pita
ORCID: https://orcid.org/0000-0002-8832-8005
E-mail: javier.pita @ifpa.edu.br
Instituto Federal de Educação, Ciências e Tecnologia do Pá, Brasil
Klewton Adriano Oliveira Pinheiro
ORCID: https://orcid.org/0000-0003-2696-4249
E-mail: klewton.pinheiro@ @mail.com
Francimary da Silva Carneiro
Instituto Federal de Educação, Ciências e Tecnologia do Pará, Brasil
ORCID: https://orcid.org/0000-0002-1693-8779
E-mail: francimarycarneiro@ @mail.com
Lecretaria de Meissa Martins Barbosa D'Arace
ORCID: https://orcid.org/0000-0002-8533-555X
Secretaria de Meio Ambiente e Sustentabilidade, Brasil
E-mail: larissamartins350@ gmail.com
Aline Cecy Rocha de Lima
ORCID: https://orcid.org/0000-0001-5887-3689
Universidade Federal do Pará, Brasil
E-mail: Alinececy@yahoo.com
Alex da Silva Frazão

\section{Resumo}

A crise ambiental vem ao longo dos anos se agravando, em função de vários problemas ambientais, decorrente, muitas das vezes pela ação devastadora do homem em querer somente benefícios econômicos. A degradação que veem ocorrendo no mundo passou a ser a maior preocupação da comunidade científica, levando-a a repensar novas estratégias para proteger o meio ambiente, a fim de garantir a sobrevivência do ecossistema global e espécie humana. A degradação dos recursos naturais favoreceu para iniciar um enfoque mundial sobre problemas relativos ao meio ambiente. Com isso, várias instituições foram criadas para debater novas proposta de preservação, surgiram várias propostas, e uma dessas propostas foi à introdução da Educação Ambiental no currículo escolar e profissionalizante. Nesta perspectiva, a Educação Ambiental representa um subsidio para fortalecer e criar uma consciência sobre a importância que o meio ambiente tem para nossa sobrevivência e que desde jovem tenhamos o cuidando com os recursos naturais. Hoje, a visão sobre a extração dos recursos naturais culminando para esse aumento da degradação e poluição, onde demanda a obrigação dos órgãos juntos aos governantes, mas eficácia nas leis, punindo com rigor aquele que degrada o planeta, resultando em um novo mecanismo jurídico de proteção dos recursos naturais.

Palavras-chave: Desenvolvimento profissional; Resolução de problemáticas; Transdisciplinar.

\begin{abstract}
The environmental crisis has increased over the years, due to several environmental problems, often resulting from the devastating action of man in wanting only economic benefits. The degradation they see occurring in the world has become the main concern of the scientific community, leading it to rethink new strategies to protect the environment in order to guarantee the survival of the global ecosystem and human species. The degradation of natural resources has favored a global approach to environmental problems. With this, several institutions were created to discuss new proposals for preservation, several proposals appeared, and one of these proposals was the introduction of
\end{abstract}


Environmental Education in the school and vocational curriculum. In this perspective, Environmental Education represents a subsidy to strengthen and raise awareness about the importance that the environment has for our survival and that since we have been taking care of the natural resources. Today, the vision on the extraction of natural resources culminating in this increase of degradation and pollution, where it demands the obligation of the organs together with the rulers, but effective in the laws, rigorously punishing the one that degrades the planet, resulting in a new legal mechanism for the protection of natural resources.

Keywords: Professional development; Problem solving; Transdisciplinary.

\section{Resumen}

La crisis medioambiental se ha ido agravando a lo largo de los años, debido a varios problemas medioambientales, resultantes, a menudo, de la acción devastadora del hombre al querer únicamente beneficios económicos. La degradación que están viendo en el mundo se ha convertido en la principal preocupación de la comunidad científica, llevándola a repensar nuevas estrategias para proteger el medio ambiente, a fin de garantizar la supervivencia del ecosistema global y la especie humana. La degradación de los recursos naturales favoreció el inicio de un enfoque global en los problemas relacionados con el medio ambiente. Con ello se crearon varias instituciones para debatir nuevas propuestas de preservación, surgieron varias propuestas, y una de estas propuestas fue la introducción de la Educación Ambiental en el currículo escolar y profesional. En esta perspectiva, la Educación Ambiental representa un subsidio para fortalecer y crear conciencia de la importancia que tiene el medio ambiente para nuestra supervivencia y que desde pequeños lo hemos cuidado con recursos naturales. Hoy, la visión sobre la extracción de recursos naturales culmina en este aumento de la degradación y contaminación, donde exige la obligación de los órganos junto con el gobierno, pero efectividad en las leyes, castigando severamente a quienes degradan el planeta, resultando en un nuevo mecanismo legal de protección de los recursos naturales.

Palabras clave: Desarrollo professional; Resolución de problemas; Transdisciplinariedad.

\section{Introdução}

O Brasil deu passos significativos para melhorar a qualidade da educação na década de 80, quando melhorou o fluxo de matrículas e investiu na qualidade da aprendizagem num contexto marcado pela modernização econômica, pelo fortalecimento dos direitos da cidadania e pela disseminação das tecnologias da informação. Nesse período, os sistemas de ensino público e privado vêm passando por processos de reforma educacional, através da Lei no 9.394/96, a nova Lei de Diretrizes e Bases da Educação Nacional (LDB), que descreveu um currículo no qual os conteúdos de ensino possam produzir aprendizagem e constituir competências nos alunos, fazendo com que a sociedade dialogue com o meio ambiente de uma forma sustentável através da educação ambiental.

A questão ambiental é um dos assuntos atuais e como estratégicos nas agendas e tratados internacionais realizados por organizações intergovernamentais, como as que fazem parte da ONU - Organização das Nações Unidas, pois, o modelo de desenvolvimento firmado a partir da Revolução Industrial impulsionou o crescimento quantitativo e qualitativo no processo de degradação da natureza (Brasil, 2001). As reuniões internacionais e nacionais indicam para uma nova forma de desenvolvimento, o desenvolvimento sustentável, no qual os princípios básicos são fundamentados na sustentabilidade social e ambiental dentro da escola (Silva \& Leite, 2013).

O histórico da educação ambiental no Brasil vem sendo demarcada desde 1972 com a conferencia de Estocolmo, ganhando fundamentação e ênfase na ECO-92 e com a Instituição da Política Nacional de Educação Ambiental em 1999, que apoiava a educação ambiental no âmbito do ensino formal quanto não formal e que tinha que ser inserido nas escolas como conteúdo interdisciplinar. Apesar de ser exigência legal, a educação ambiental é ainda difícil de ser desenvolvida, requerendo atitudes concretas e mudanças de comportamento dos cidadãos, principalmente quando se pensar trabalhar a Educação Ambiental respeitando todos os atores sociais e o meio ambiente (Narcizo, 2009).

No entanto, Boutinet (2002) cita em sua pesquisa que encontrou confusões de entendimento no campo educacional, provocadas por uma tentativa de fazer mudança no rigido programa escolar ao tentar resolver os problemas de aprendizagem dos alunos. Lamosa (2011) comenta que as dificuldades enfrentadas para a inclusão da EA nas escolas está na precariedade de recursos materiais e humanos, bem como a falta de previsão de tempo para planejamento e realização de atividades 
extracurriculares. No ensino médio integrado a educação profissional técnica o currículo integrado foi apontado como vilão na formação básica e profissional por apresenta diferentes concepções gerando prejuízos para o aprendizado.

Por isso, a reflexão a respeito dos costumes sociais, em uma realidade marcada pela constante degradação do meio ambiente e dos seus recursos naturais, resulta em uma articulação essencial com a formação de consciência sobre a educação ambiental. $\mathrm{O}$ aspecto ambiental caracteriza-se como um parâmetro que engloba um conjunto de agentes de meio educativo, fortalecendo o comprometimento dos vários sistemas de conhecimento, a qualificação de profissionais e da comunidade acadêmica em uma concepção interdisciplinar.

Nesse âmbito, a construção de conhecimento deve obrigatoriamente abranger as correlações do meio ambiente com a sociedade, incluindo o estudo dos fatores determinantes no processo, a função dos atores envolvidos e os diversos modos de organização social que estimulam a capacidade das ações de desenvolvimento que priorizem a sustentabilidade socioambiental (Jacobi, 2003).

A educação ambiental deve ter como propósitos proporcionar uma qualidade de vida adequada e a erradicação da pobreza e do modelo de consumo descontrolado, pois através da educação pode-se fundamentar ideias, proporcionando aos indivíduos um entendimento crítico e amplo do meio ambiente, assim como permitir a aquisição valores, bem como construir práticas que lhes permitam ter um posicionamento consciente e participativo sobre as questões referentes a conservação e utilização sustentável dos recursos naturais (Medina, 2002).

Nesta lógica, a educação ambiental é essencial para entender as inúmeras modificações da realidade geradas pela problemática do desenvolvimento. O processo de formação provoca um ensino mais orgânico e reflexivo das instituições do conhecimento e da sociedade na construção de novas habilidades para entender e interceder na transformação global (Jacobi, 2003).

Diante do exposto, esta pesquisa tem o propósito de tecer discussões a respeito da importância da educação ambiental para a formação profissional, como uma estratégia de promover a consciência ambiental dos educadores e dos futuros profissionais sobre a atual situação do planeta.

\section{Metodologia}

A metodologia aplicada na realização deste trabalho foi uma revisão bibliográfica baseada em pesquisa de artigos científicos já publicados e livros. Foi realizada uma análise de títulos e resumos para obtenção de artigos potencialmente relevantes para a revisão.

Para critério de inclusão, os artigos deveriam se relacionar à educação ambiental, com um enfoque principal de benefício para formação de profissionais técnicos e graduados, nas áreas das agrárias. Artigos relacionados às práticas, experiências, teorias, foram sistematizadas a fim de fortalecer, consolidar e estimular a educação ambiental para formação.

\section{Resultados e Discussões}

\subsection{Base conceitual da educação Ambiental}

A Educação Ambiental (EA) vem sendo bastante debatido por pesquisadores e movimentos ambientalistas, no contexto nacional e mundial, nos últimos anos, estando em visibilidade nas pautas de políticas públicas educacionais e sistemas de ensino, inclusive nos currículos escolares, com temas abordando a interdisciplinaridade em todas as modalidades de ensino (Moura, 2015).

A temática que entorna a "Educação", como caminho para o entendimento da instrução, percepção Ambiental e Educomunicação, está embasada em aspectos inter-relacionados e interligados, em que se iniciam pelo conceito da educação, seu desenvolvimento histórico cultural, a evolução do pensamento. Em seguida, busca-se o significado da Educação Ambiental 
e sua evolução no tempo. Outrora, existia uma confusão por se entender que a educação era sinônimo de obediência. Dias (2000, p.13) descreve que:

E o aprendizado era imposto por meio do respeito forçado, de castigos ou tarefas, o que não encorajava os educandos a compreenderem reflexivamente sobre o conteúdo proposto, podendo, até mesmo, irritá-los. Mas, nos últimos anos, tem havido mudanças no modo de ensinar, tanto nas escolas quanto nas universidades. Metodologias diferentes e novas tecnologias de apoio fizeram com que a educação passasse por várias fases, processo este que faz parte da história do Brasil e de outros países.

Desta forma, é preciso arquitetar uma educação que objetive libertar a sociedade do determinismo, passando a compreender a função da História e onde a temática da identidade cultural, tanto em seu aspecto individual, como em relação à categoria dos professores, Assim torna-se fundamental uma prática pedagógica que conduza um processo de ensino e aprendizagem dinâmico e não estático e pontual. É preciso respeitar essa identidade, com autonomia, levando em consideração as experiências vividas pelos educandos antes de chegar à escola, para que o processo seja operante, e não apenas meras palavras sem significado real (Freire, 1996, p. 28-33).

A participação e a integração são a cerne da aprendizagem política e da consciência formadora, que fortalece a gestão da sociedade. "Uma escola, um lar, uma comunidade, enfim, de um ambiente, e é por meio dela que vinculamos a educação à cidadania e estabelecemos os elos para formulações transdisciplinares e ampliadas acerca da realidade" (Loureiro, 2004, p.18).

Novas abordagens, integrando as várias áreas de conhecimentos, precisam ser criadas para o meio ambiente no intuito o despertar da consciência, principalmente das crianças e dos adolescentes, para que assim novos hábitos possam ser formados, direcionando a espécie humana a utilizar os recursos naturais de forma sustentável (Souza et al., 2013).

\subsection{Aspectos Históricos da Educação Ambiental}

O ser humano historicamente tem procurado modos de difundir no meio ambiente práticas para sua qualidade de vida, este condicionamento tem promovido em paralelo uma transformação intensa na paisagem e nos ecossistemas naturais, provocando profundas mudanças estruturais nas dinâmicas naturais, as quais de certa forma tem se mostrado desfavorável a uma vida sustentável (Dias, 2000, p.17).

A globalização econômica, a revolução da informação, consumo e a não consciência humana tem de certa forma contribuído para os crescentes problemas ambientais vivenciados pelas sociedades pelo mundo, esses fatores tem tornado o planeta vulnerável, à medida que favorecem um uso dos recursos naturais finito de forma descontrolada. Portanto, chegamos ao limite explorável dos recursos naturais, fato que faz com que a educação venha para defender e mostrar nova postura quanto ao uso dos recursos naturais e o trato com o meio ambiente, como garantia desses recursos e de um ambiente agradável para as futuras gerações (Passos, 2009).

A Educação Ambiental vem se tornando frequentes nos debates coletivo e participativo. O acesso à informação sobre o meio ambiente, ao conhecimento sobre degradação ambiental e saberes locais de agentes poluidores, destacando-se no cenário nacional e internacional, por meio de encontros, seminários, políticas públicas e legislações (Moura, 2015).

Numa cronologia de tempo, podemos citar a Conferência de Estocolmo, em 1972, a Constituição Federal Brasileira de 1988, a ECO-92, a Lei de Diretrizes e Bases da Educação Nacional - LDB 9394/96 (Brasil, 1996), a Resolução CNE/CP 1/2012 (Brasil, 2012 b), que estabelece Diretrizes Curriculares em Direitos Humanos (DCN) e, por último, a Resolução CNE/CP 2/2012, que estabelece Diretrizes Curriculares Nacionais para a Educação Ambiental (DCN), a Rio + 20.

A realização da Conferência Intergovernamental sobre Educação Ambiental, em Tsibilisi (EUA), no ano de 1977, deu início a um abrangente processo a nível mundial direcionado para elaborar as condições necessárias para construir uma nova consciência a respeito das riquezas naturais e para recriar a produção de conhecimento fundamentadas na estratégia da 
interdisciplinaridade e nas teorias da complexidade. Segundo algumas de suas normas criadas durante esta conferência, a educação ambiental no meio acadêmico deveria acabar com as formas tradicionais de educação ao aderir a interdisciplinaridade como solução para os problemas socioambientais e elaborar materiais pedagógicos e estabelecer colaborações locais, nacionais e internacionais, assim como incorporar no programa de formação de docentes a educação ambiental (Unesco, 1994).

No Brasil, o fortalecimento da vertente transformadora da educação ambiental, iniciou-se em 1980. Potencializado pela aproximação de educadores e também de envolvidos com educação popular e instituições públicas de educação, paralelamente, aos militantes de movimentos sociais e ambientalistas. O grande enfoque era a transformação societária, baseada nos questionamentos dos padrões industriais e de consumo firmados no capitalismo (Loureiro, 2004, p.67).

A questão da sustentabilidade ambiental apresenta, neste novo século, um papel primordial na reflexão a respeito das perspectivas do desenvolvimento e das novas que alternativas que são demandadas. A realidade ambiental e social que define as sociedades contemporâneas mostra que os impacto das diversas explorações sobre os recursos naturais tem gerado consequências cada vez mais complexas e difícil de elaborar soluções adequadas (Jacobi, 2003).

\subsection{Educação ambiental: experiências, pesquisas e práticas}

Os recentes problemas ambientais e crise do conhecimento científico requer um novo papel das instituições de ensino. Deste modo, as instituições técnicas são convidadas a adotarem um novo posicionamento que seja mais reflexivo e crítico a respeito das questões ambientais, com a finalidade de construir um pensamento que impulsione à transformação de paradigmas científicos tradicionais e a possibilitar novas formas de conhecimentos e maior integração das diversas áreas do saber, com a cooperação da sociedade (Morales, 2013).

Neste âmbito, existem inúmeros trabalhos que objetivam levantar informações a respeito da educação ambiental e incentivar essa prática de ensino dentro das instituições. Morales (2013) realizou um estudo com a finalidade de construir discussões sobre as instituições universitárias, para debater o seu papel e repensar sobre a sua função no processo de formação na área da educação ambiental, visando principalmente os cursos de pós-graduação, com a intenção de analisá-los e compreendê-los. Com isso, o autor executou um mapeamento dos diversos cursos de especialização em educação ambiental presentes no Brasil, e constatou que existe um número expressivo de profissionais de diferentes áreas do conhecimento que procuram a oportunidade de se aprofundar e adquirir uma discussão mais ampla a respeito da relação entre sociedade e natureza.

Verdi e Pereira (2012), em seu estudo, buscaram avaliar a inclusão da dimensão ambiental nos cursos de formação de educadores da Universidade Regional de Blumenau - FURB, assim como nas atividades de pesquisa e extensão da instituição. Verificou-se que existem diversas integrações de assuntos ambientais nas atividades de ensino, pesquisa e extensão da FURB, contudo ocorrem isoladamente, não oferecendo um subsídio institucional adequado para a formação de professores ambientais nos cursos de licenciatura. Esse processo de formação precisa ser ofertado no ensino superior, pois os educadores necessitam estar capacitados para educar uma nova geração consciente, crítica e capaz de entender e administrar os problemas ambientais.

Silva e leite (2013) realizaram trabalho com a finalidade de desenhar estratégias que viabilizem a execução da Educação Ambiental nas instituições de Ensino Fundamental, a fim de contribuir para a inserção das questões ambientais no currículo, melhorar a qualidade de vida e para viabilizar a construção de escolas mais sustentáveis. Desta forma, as estratégias desenvolvidas destacaram-se: a reconhecimento da percepção ambiental; construção de análises ambientais, cooperação de toda comunidade das instituições e capacitação de professores para execução da Educação Ambiental dentro dos parâmetros e diretrizes internacionais e nacionais. A formação de educadores na área ambiental, através de estratégias metodológicas 
empregadas de modo dinâmico, criativo, recreativo, apoiado na relação afetiva entre os atores é a estratégia primordial para alcançar o desenvolvimento da Educação Ambiental nas instituições de ensino fundamental.

Tozoni-Reis (2002) também realizou um estudo a respeito da educação ambiental, nesta pesquisa a autora aborda os pressupostos teóricos existentes na capacitação dos docentes da área ambiental nos diversos cursos de graduação das universidades. A partir dos procedimentos metodológicos empregados neste estudo, constatou-se que a análise das tendências avaliadas mostra um crescimento de superação dos paradigmas tradicionais presentes em grande parte das organizações curriculares das instituições de ensino superior.

Outra importante pesquisa realizada sobre educação ambiental foi executada por Oliveira et al. (2007), onde os autores buscaram distinguir as perspectivas e práticas pedagógicas dos educadores de Ciências no que diz respeito à educação ambiental no ensino fundamental, fazendo surgir dos argumentos desses profissionais suas possíveis soluções para incentivar uma maior conscientização quanto às questões socioambientais. Na maioria das respostas, as opiniões sobre a educação ambiental dos entrevistados são fundadas em conceitos comumente desprendidas de um plano de trabalho que possa fomentar a formação de cidadãos críticos, capazes de produzirem conhecimento através da mudança de valores e de uma maneiro mais ética perante as questões ambientais.

As inúmeras pesquisas e experiências que estão sendo desenvolvidas no âmbito da educação ambiental são de extrema importância para sociedade, pois essas práticas corroboram para o aperfeiçoamento e capacitação dos educadores ambientais que poderão contribuir para uma melhor formação profissional, levando em consideração a relação do meio ambiente com a sociedade.

\subsection{Importância da educação ambiental para formação profissional}

Com as muitas transformações sociais geradas pelo desenvolvimento do conhecimento científico, as tecnologias tornaram-se parte inseparáveis das atividades humana, e apresenta grande relevância, também, para as relações sociais, políticas e econômicas da maior parte da população. Os atores agem e interagem de muitas maneiras possíveis, empregando as ferramentas tecnológicas construídas a partir do acúmulo de conhecimento que foi realizado e constituído nas circunstâncias das relações do ser humano com a natureza, levando em consideração as especificações de cada período da história (Oliveira et al., 2007, p. 2).

A forma de desenvolvimento econômico praticada há muitos anos causou muitos problemas ambientais e sociais. Essas problemáticas podem piorar ainda mais com a ausência da preocupação da prática pedagógica em relação à formação de cidadãos mais conscientes. A maior parte dos educadores não está adequadamente capacitada para adentrar em discussões com seus alunos sobre assuntos que abordem às questões ambientais de forma crítica (Reigota et al., 2003, p. 9).

A Educação Ambiental gerou várias soluções para os problemas do ser humano em sociedade, haja vista que desde criança ao adulto se saibam a importância do meio ambiente para a sobrevivência da humanidade, proporcionando uma maior sustentabilidade aos recursos naturais (Souza et al., 2013).

Contudo, o papel do professor como educador é de fundamental importância na tarefa de conscientizar e transformação as crianças e jovens que podem se tonar a solução para este problema. Portanto, necessita-se trabalhar a educação ambiental em todos os níveis da educação, visto que é de suma importância para a sobrevivência humana (Cichella et al., 2007). Entretanto, temos que valorizar os currículos, meio ambiente, percepção e educação ambiental, permitir a firmação de valores, atitudes, práticas sociais e expressar a cultura dos direitos humanos nos espaços sociais e na escola, envolvendo a sociedade e a natureza como fonte de vida. 
Para tanto, como preconiza a Resolução CNE/CP 1/2012 e a Resolução CNE/CP 2/2012 (Brasil, 2012 c), é importante relacionar a dimensão ambiental à justiça social, aos direitos humanos e sociais, à saúde, ao trabalho e consumo, à pluralidade étnico-racial e de gênero, à diversidade sexual, à superação do racismo e de todas as formas de discriminação e injustiça social.

\section{Considerações Finais}

O meio ambiente provem diversos serviços ecossistêmicos que dão suporte à vida, no entanto, as sociedades não estão direcionando os devidos valores e importância a esses serviços, pois constantemente o mesmo vem sofrendo perdas irreparáveis associadas a mudanças nas paisagens naturais em função de atividades humanas direcionadas ao uso dos recursos naturais.

A exploração desenfreada dos recursos naturais através das mais diversas intervenções humanas tem mostrado o quanto os ecossistemas são vulneráveis às progressivas pressões humanas sofridas. Assim, o homem por falta de uma maior consciência em relação ao uso mais racional tem contribuído incessantemente neste processo.

Vale ressaltar que os problemas ambientais vivenciados não se tratam somente de uma questão ambiental, pois atrelado a esta tem-se as questões sociais que irão direcionar a médio e longo prazo a forma e a qualidade de uma vida futura das populações no planeta.

Nessa perspectiva, nos encontramos em tempos de repensarmos nossas atitudes quanto ao uso dos recursos naturais e a forma como lidamos com o meio ambiente. Torna-se, portanto, necessário que ocorra um processo participativo e mais sustentável das sociedades na busca do equilibro entre os homens e meio natural, e assim todos estarão contribuindo de forma mais ampla com a redução e ou mitigação dos problemas hoje existentes.

Nesta lógica, constata-se a necessidade de uma maior conscientização das sociedades em relação as problemáticas ambientais vivenciadas, no entanto, um conhecimento que ainda está em construção, exige esforço para fortalecer perspectivas integradoras que incentivem uma reflexão a respeito da diversidade e a construção de novos pensamentos em torno das interações entre sociedade e da natureza, dos riscos ambientais e das relações de desenvolvimento e meio ambiente.

Portanto, a educação ambiental, em suas inúmeras possibilidades, abre um grande espaço para pensar e executar práticas sociais e a função dos professores como intermediários e transmissores de um conhecimento necessário e muito importante para que os futuros profissionais nas mais diversas áreas do conhecimento possam adquirir um suporte necessário para compreender de forma crítica e consciente as diversas realidades do meio ambiente e apresentar possíveis soluções e estratégias ambientalmente sustentáveis.

Assim torna-se necessário uma maior introdução do assunto nas escolas e nas universidades como disciplina essencial para a formação dos cidadãos e dos futuros profissionais, onde estes sejam moldados a formarem opiniões e conceitos sustentáveis para que tenhamos uma sociedade mais justa, igualitária e desenvolvida nas premissas da sustentabilidade.

\section{Referências}

Boutinet, J. P.( 2002). Antropologia do projeto. Artmed, (5a .ed.) 218 p Trad. Patrícia Chitonni Ramos.

Brasil. (2001). Parâmetros em Ação; Meio Ambiente na escola. Ministério da Educação e do Desporto. Secretaria de Educação Fundamental. Brasília.

Cichella, F., Coelho, J. M. S., \& Resendes, L. M. (2007). Educação ambiental: Direcionando a busca. http://www.satc.edu.br/satc/fotos/2007/860/3_forum_ambiental.pdf.

Dias, G. F.(2000). Educação ambiental. Princípios e práticas, (6a ed.) Editora Gaia, 552.

Freire, P.(1996). Pedagogia da autonomia: saberes necessários à prática docente: Paz e Terra, p. 25. 10.18764/2446-6549.2019.10355.

Jacobi, P. (2003). Educação ambiental, cidadania e sustentabilidade. Cadernos de pesquisa, 118(3), 189-205. https://doi.org/10.1590/S010015742003000100008 . 
Research, Society and Development, v. 10, n. 2, e9010212291, 2021

(CC BY 4.0) | ISSN 2525-3409 | DOI: http://dx.doi.org/10.33448/rsd-v10i2.12291

Lamosa, R. A. C., \& Loureiro, C. F. B. A. (2011). Educação Ambiental e as políticas educacionais: Um estudo nas escolas públicas de Teresópolis (RJ), Educação e Pesquisa, 37(277)- 292. https://doi.org/10.1590/S1517-97022011000200005.

Loureiro, C. F. B.(2004). Educação ambiental transformadora. Identidades da educação ambiental brasileira. Brasília: Ministério do Meio Ambiente, 67. https://smastr16.blob.core.windows.net/cea/cea/ident_eabras.pdf.

Loureiro, C. F. B. (2004). Educar, participar e transformar em educação ambiental. Revista Brasileira de Educação Ambiental, 0, p. 18. http://docente.ifsc.edu.br/marco.aurelio/Material\%20Aulas/Especializa\%C3\%A7\%C3\%A3o\%20Tecnologias\%20Educacionais/Sustentabilidade, \%20Cidadani a\%20e\%20Educa\%C3\%A7\%C3\%A3o/Artigos/4080-11409-1-PB.pdf\#page=13.

Medina, N. M. (2002) Formação de multiplicadores para educação ambiental. O contrato social na ciência unindo saberes na educação ambiental. Org: PEDRINI: Vozes. http://www.luzimarteixeira.com.br/wp-content/uploads/2011/04/multiplicadores-para-educacao-ambiental.pdf.

Moura, J. S. R. (2015). Educação ambiental no currículo do curso técnico profissional em nutrição do centro estadual de Educação profissional y, ItabunaBA, Itapetinga - BA. Dissertação de Mestrado em Ciências Ambientais do PPG em Ciências Ambientais da Universidade Estadual do Sudoeste da Bahia, Campus de Itapetinga, BA. 147p. http://www2.uesb.br/ppg/ppgca/wp-content/uploads/2017/11/DISSERTA\%C3\%87\%C3\%83O-ENVIADA-AO-PPGCA-PPDF.pdf.

Morales, A. G. M. (2013). O processo de formação em educação ambiental no ensino superior: trajetória dos cursos de especialização. REMEA-Revista Eletrônica do Mestrado em Educação Ambiental, 18. https://doi.org/10.14295/remea.v18i0.3554.

Narcizo, K. R. S. (2009). Uma análise sobre a importância de trabalhar educação ambiental nas escolas. REMEA-Revista Eletronica do Mestrado em Educação Ambiental. 22. https://doi.org/10.14295/remea.v22i0.2807

Oliveira, A. L., Obara, A.T., \& Rodrigues, M. A. (2007). Educação ambiental: concepções e práticas de professores de ciências do ensino fundamental. Revista Electrónica de Enseñanza de las Ciencias, 6(3), 471-495.

Passos, P. N. C. A. (2009). Conferência de Estocolmo como ponto de partida para a proteção internacional do meio ambiente. Revista Direitos Fundamentais \& Democráticos. 6, p. 25.

Reigota, M., Possas, R., \& Ribeiro, A. (2003). Trajetórias e narrativas através da educação ambiental: DP\&a. 160 p.

Souza, G. S., Machado, P. B., Reis,V. R., Santos, A. S., \& Dias ,V. B.( 2013). Educação ambiental como ferramenta para o manejo de resíduos sólidos no cotidiano escolar. Revista Brasileira de Educação Ambiental (RevBEA), 8(2), 118-130.

Da Silva, M. M. P., \& Leite, V. D. (2013). Estratégias para realização de educação ambiental em escolas do ensino fundamental. REMEA-Revista Eletrônica do Mestrado em Educação Ambiental, v. 20.

Tozoni-Reis, M. F. C.(2002). Formação dos educadores ambientais e paradigmas em transição. Ciência \& Educação (Bauru), 8(1), 83-96.

UNESCO-Organização das Nações Unidas para a Educação, a Ciência e a Cultura. (1994). Programa Internacional de Educación Ambiental. Estrategias para la formación del profesorado en educación ambiental: CENEAN, libros de la Catarara, n. 25.

Verdi, M., \& Pereira, G. R. (2012). A educação ambiental na formação de educadores-O caso da Universidade Regional de Blumenau-FURB. REMEARevista Eletrônica do Mestrado em Educação Ambiental, 17. 